\title{
Aspects of liver transplant pathology with emphasis on rejection and its mechanisms
}

\author{
D G D Wight
}

\section{Introduction}

Liver transplantation has in the past few years evolved from a semi-experimental procedure practised in only a few European and North American centres to an almost routine worldwide treatment for a whole range of liver diseases. ${ }^{12}$ Concurrently, one year survival has improved from less than $50 \%$ to more than $90 \%$ for certain diagnoses such as biliary atre$\mathrm{sia}^{34}$ most survivors being able to resume a normal lifestyle. Furthermore, the rate of liver graft loss beyond one year is much lower ${ }^{5}$ than for renal $^{6}$ and other grafts. Although the surgery and immediate postoperative care are confined to specialist units, further follow up is often undertaken in the patient's local hospital and so more and more clinicians and pathologists are coming into contact with this group of patients.

After removal from the donor the liver is perfused with preservation fluid and stored at $4^{\circ} \mathrm{C}$ while being taken to the recipient. Injury or poor preservation at this time may lead to subsequent poor graft function..$^{7}$ It is then inserted into the right hypochondrium, with restoration of normal vascular and biliary connections. The graft can be monitored by blind core biopsy, fine needle aspiration biopsy, ${ }^{9}$ or bile cytology. ${ }^{1011}$ Needle biopsy has the advantage that it is possible to assess architecture as well as cellular detail, but has a higher complication rate. It is important to stress that the interpretation of transplant biopsies is not always straightforward. By contrast with the position in routine biopsy practice, where one expects to find a unifying single disease to explain the patient's illness, more than one diagnosis is extremely common in transplant material. There may often-for example, because it is so common, be evidence of rejection together with some other condition such as bacterial infection. These difficulties often magnify with increasing time after the operation. ${ }^{12}$ Also, abnormalities may be focal and so it is most important to examine all the stained sections. Nevertheless, biopsy is one of the most important and useful tools available in the investigation of post-transplant liver dysfunction. ${ }^{13-19}$ Fine needle aspiration biopsy is particularly useful for monitoring the quality of the infiltrate in acute cellular rejection, because, especially with the help of monoclonal or polyclonal antibodies, the identification of individual cell types may be easier than in histological preparations. ${ }^{20}$

The table shows the principal complications. As there is a large body of recent publications, ${ }^{21-24}$ only selected complications will be discussed, with particular emphasis on rejection and its mechanisms.

\section{ACUTE REJECTION}

Acute cellular graft rejection is common and in most series affects about $70 \%$ of all grafts. The principal targets of rejection are found in portal tracts, which are therefore the site of the rejection triad of portal tract inflammation, endotheliitis, and bile duct damage. ${ }^{25}$ Endotheliitis may affect the hepatic venules, but parenchymal inflammation is unusual. The infiltrate is composed predominantly of lymphocytes but always includes significant numbers of activated or blast cells, which seem in all cases to include both CD4 + and CD8 + cells. Blast cells received scant attention until those groups using fine needle aspiration biopsy demonstrated their true significance. ${ }^{9}$ They are now regarded as probably the most important single marker of acute rejection. ${ }^{24}$ Also, there are macrophages, and in most cases both eosinophils and neutrophils. Parenchymal changes such as canalicular cholestasis and hepatocyte ballooning are common, but may as often be related to the quality of the graft or post-perfusion injury as to rejection. The intensity of the infiltrate is often variable and thus interpretation can be misleading unless a series of levels is examined from each biopsy. Some attempts have been made to grade the infiltrate. Most such schemes are based on quantitative assessments of the inflammatory infiltrate but none has gained wide acceptance. ${ }^{2124} 26$

Neutrophil polymorphs may cause diagnostic confusion in transplant biopsies. Neutrophils are prominent in suppurative cholangitis, ${ }^{27}$ but their presence does not necessarily imply infection. They are sometimes prominent in biopsies with otherwise typical acute rejection, ${ }^{28}$ a finding described as rejection cholangitis. Here, they may be the consequence of leakage of biliary constituents after

\section{Complications of liver transplantation}

\begin{tabular}{lc}
\hline $\begin{array}{l}\text { Complications that } \\
\text { affect the graft }\end{array}$ & $\begin{array}{c}\text { Complications that } \\
\text { affect the host }\end{array}$ \\
\hline Technical: & Infection: \\
Vascular thrombosis & Bacterial \\
Bile duct leak or stenosis & Viral \\
Primary non-function & Fungal \\
Rejection: & Graft versus host \\
Hyperacute & disease \\
Acute & \\
Chronic & New tumours: \\
Disease recurrence: & Lymphoproliferative \\
Malignant tumours & Epithelial \\
Viral hepatitis & \\
Budd-Chiari syndrome & \\
Autoimmune CAH & \\
Primary sclerosing cholangitis? & \\
Primary biliary cirrhosis? & \\
Drug toxicity: & \\
Azathioprine & \\
\hline
\end{tabular}


immunologically mediated bile duct damage. They appear unduly prominent after treatment by steroids, which destroys lymphocytes but not neutrophils. Both hepatitis $B$ and hepatitis $C$ have a high recurrence rate after liver transplantation. Both are associated with lymphocytic infiltration of portal tracts, but both the timing and the quality of the infiltrate are rather different from those seen in rejection. Hepatitis does not usually recur in less than four weeks and the cellular infiltrate is then composed mainly of lymphocytes, with or without germinal centres, and plasma cells. Immunocytochemistry or in situ hybridisation for viral antigens may resolve the issue.

The main targets of rejection are thought to be the class I and class II antigens of the major histocompatibility complex. Both are strongly expressed on the principal antigen presenting cells, the dendritic cells, which in the liver are found mainly in the portal connective tissuea distribution that probably explains why inflammation is centred on portal tracts. Endothelia and bile duct epithelium normally only express class I antigens, whereas hepatocytes express neither. The absence of surface HLA molecules from normal hepatocytes might seem to explain their relative protection from the rejection process. Enhancement or new expression of HLA molecules of both classes occurs, however, probably in response to a variety of cytokines, not only in rejection but also in many inflammatory conditions affecting the liver. Thus hepatocytes do acquire a honeycomb-like pattern of membrane expression of class I antigen during rejection, but they remain unattacked by lymphocytes. The explanation may be a simple anatomical one, that lymphocytes cannot normally gain access to the space of Disse and thus to the hepatocyte membrane. Bile duct epithelium, which also shows new expression of class II molecules, by contrast, presents a fully exposed target to the immune system.

Cellular adhesion molecules play a major part in cellular interactions by lymphocytes, and it is clear that several play an important accessory part in graft rejection. The best studied is perhaps ICAM-1, and its expression has been shown to be enhanced during liver transplant rejection, when its appearance precedes lymphocyte activation. ${ }^{29}$ This response is more specific than major histocompatibility complex molecule upregulation, and may also have some value as a predictor of chronic rejection when strongly expressed on biliary epithelium. ${ }^{30}$ Antibody to ICAM-1 may be an effective immunosuppressive by blocking effector function, even though it does not prevent $T$ cell recruitment or activation. ${ }^{31}$ Introduction of such an antibody into clinical practice would have a profound effect on the diagnosis of rejection by conventional histological methods.

Acute rejection occurs most often between one and two weeks after transplantation, and is usually easily controlled by a short course of steroids. Recurrence is unusual. Early acute rejection is probably so vigorous because it is due to direct recognition of peptide presented by allogeneic major histocompatibility complex molecules on antigen presenting (mainly dendritic) cells of donor origin. ${ }^{32}$ As the allogeneic cells are destroyed (but see graft acceptance later) donor antigens must be processed by antigen presenting cells of recipient origin that repopulate the graft. Presentation is now by recipient major histocompatibility complex molecules (so called indirect recognition), and is easily controlled by basic background immunosuppression.

Cellular effector mechanisms of graft destruction remain unclear; however, because of its extreme selectivity whereby syngeneic cells are left intact while adjacent allogeneic cells are destroyed, specific CD8 + mediated cytotoxicity is thought to be the major mediator. ${ }^{32}{ }^{33} \mathrm{CD} 4+\mathrm{T}$ helper cells are almost certainly also required to provide help but not necessarily effector function. This probably explains why both $\mathrm{CD} 4+$ and $\mathrm{CD} 8+$ cells are seen in near equivalent numbers in rejecting liver grafts. ${ }^{34}$ Blood and graft eosinophils have been consistently linked with rejection reactions, ${ }^{35}$ and recent evidence suggests that IL5, ${ }^{36}$ a T cell cytokine, may be responsible for their recruitment. ${ }^{37}$ Major basic protein, a cytotoxic mediator produced by the eosinophils, may then contribute to the graft damage. ${ }^{38}$

\section{ANTIBODY MEDIATED REJECTION}

Antibody mediated rejection is unusual in hepatic grafts even when performed across ABO blood group barriers and therefore in the presence of preformed antibodies. ${ }^{39}$ Kidney and heart grafts in such circumstances are destroyed by extensive vascular thrombosis within minutes, but livers often survive unharmed, although the graft loss is higher than that after transplantation of matched organs. ${ }^{4041}$ In clinical practice, ${ }^{42-45}$ as well as being much rarer than after kidney grafts, the speed of onset is also slower and thus it should perhaps more properly be called accelerated rather than hyperacute rejection. In retrospect, many of the cases of sudden acute graft failure described by different authors under various names may also be examples of antibody mediated rejection. ${ }^{46}$ Finally, some cases of vascular thrombosis may properly be attributable to severe rejection rather than to technical factors. ${ }^{47} 48$

The pathology is similar to that in other organs, with haemorrhagic necrosis, vascular thromboses, and immunoglobulins deposited in vessel and sinusoidal walls. ${ }^{49}$ The mechanism of the relative resistance of the liver to antibody mediated rejection is not entirely understood. ${ }^{50}$ The liver has no true end arteries, but instead the major part of the hepatic microvasculature consists of sinusoids lined by a vast number of macrophages, the Kupffer cells, which have a great capacity for removing complexes. Again by unknown mechanisms, the liver can also release large quantities of soluble class I HLA antigen ${ }^{51}$ capable of mopping up large quantities of antibody. Thus for these anatomical and functional reasons the liver might be expected to be relatively resistant to antibody mediated damage. 
CHRONIC REJECTION

Chronic rejection, by analogy with that in other organs, is generally defined morphologically rather than in terms of time, and may occur at any time from a few weeks to more than a year after transplantation. ${ }^{24}$ The two principal components in the liver are foam cell endovasculitis and vanishing bile ducts, both of which may exist independently,,$^{52}$ plus secondary factors such as liver cell loss and cholestasis. The vasculopathy affects medium sized and large arteries of a calibre not normally seen in biopsies, and thus histological diagnosis is mainly dependent on the recognition of bile duct depletion in serial biopsies. Unfortunately, if bile duct loss is less than complete, there is some evidence that it may be reversible $^{53}$ and thus in such cases additional evidence, as for example from high resolution hepatic artery angiography, ${ }^{54}$ is required before the diagnosis can be confirmed.

The pathogenesis of chronic rejection is of considerable interest. It is uncertain whether the arterial endothelium, the media, or the adventitia is the primary target of attack, ${ }^{55-57}$ but in all organs the end result is the same. The lumen of the vessel becomes narrowed by subintimal foam cells derived mainly from macrophages, which eventually are replaced by fibromuscular intimal thickening. The subsequent arterial ischaemia then may contribute to liver cell and bile duct loss. The main cause of bile duct loss, however, is thought to be the end result of the duct damage seen in acute rejection (although this may not always be documented), and is an exact (inverse) counterpart of the hepatic lesion in graft versus host disease. ${ }^{58-60}$

Chronic rejection only affects some $5 \%$ $20 \%$ of grafts ${ }^{24}$ and risk factors for its development in an individual patient have been difficult to define. By analogy with renal transplants, where there is a close relation between late graft failure and HLA mismatches, ${ }^{6}$ it was expected that similar results would occur in liver grafts. The results have been inconsistent, however, and no clear pattern has emerged. ${ }^{24} \mathrm{~A}$ recent report suggests that full matching for class I HLA antigens may even have an adverse effect on graft survival. ${ }^{61}$ There is similar controversy over the role of infection by the cytomegalovirus. In some centres there seems to be clear evidence of an association between cytomegalovirus infection and the development of chronic rejection. ${ }^{6263}$ Cytomegalovirus is known to increase expression of class II HLA antigen on biliary epithelium, and, interestingly, the virus shows some sequence homology with class I HLA antigen. ${ }^{64}$ It remains unclear, however, whether the virus has the role of aetiological agent as proposed by the authors ${ }^{63}$ or of an innocent bystander..$^{65}$ Other units, notably that at the Mayo clinic, ${ }^{66}$ have found no association between chronic rejection and cytomegalovirus infection either alone or in relation to class I or class II matching.

\section{GRAFT ACCEPTANCE}

Although most attention has been paid to the complications of liver transplantation, as already stated, up to $90 \%$ survive long term. Starzl and his colleagues at Pittsburgh ${ }^{67} 69$ have taken a great interest in long term survivors of both liver and other organ transplants. It has long been known that grafts are permanently repopulated by lymphoreticular cells, particularly the Kupffer cells in the case of the liver, ${ }^{70}$ of recipient origin, but until now little notice has been taken of traffic in the reverse direction. That it exists has been implicit in the observation that after liver transplantation for certain metabolic diseases, such as type IV glycogen storage disease, the accumulated deposits of abnormal glycogen are cleared from the tissues such as the heart in which they are deposited. ${ }^{71}$ This could only occur if donor leucocytes were acting as enzyme carriers to the extrahepatic sites. ${ }^{69}$ Subsequently, Starzl's group has produced conclusive evidence of cells of donor origin in the host tissues of a whole range of long surviving transplant patients some of whom were no longer taking immunosuppression. ${ }^{67-69}$ They propose that graft acceptance is therefore the product of a balanced mutual natural immunosuppression between recipient and donor cells, ${ }^{69}$ although other explanations are possible, ${ }^{72}$ even that the chimaera is the consequence of the tolerance rather than its cause. ${ }^{73}$ Nevertheless, these findings have certainly opened many new channels for future research.

1 Starzl TE, Demetris AJ, van Thiel DH. Liver transplantation. N Engl F Med 1989;321:1014-22.

2 Starzl TE, Demetris AJ, van Thiel DH. Liver transplantation. N Engl f Med 1989;321:1092-9.

3 Bismuth H, Castaing D, Ericzon BG, et al. Hepatic transplantation in Europe. First report of the European Liver Transplant Registry. Lancet 1987;ii:674-6.

4 Otte JB. Recent developments in liver transplantation. Lessons from a 5-year experience. $\mathcal{f}$ Hepatol 1991;12 386-93.

5 Backman L, Gibbs J, Levy M, et al. Causes of late graft loss after liver transplantation. Transplantation 1993;55: 1078-82.

6 Takemoto S, Terasaki PI, Cecka JM, Cho YW, Gjertson DW. Survival of nationally shared, HLA-matched kidney transplants from cadaveric donors. The UNOS Scientific Renal Transplant Registry. $N$ Engl f Med 1992;327:834-9.

7 Goldstein NS, Hart J, Lewin KJ. Diffuse hepatocyte ballooning in liver biopsies from orthotopic liver transplant patients. Histopathology 1991;18:331-8.

$8 \mathrm{Ng}$ IOL, Burroughs AK, Rolles K, Belli LS, Scheuer PJ. Hepatocellular ballooning after liver transplantation: light and electronmicroscopic study with clinicopathological correlation. Histopathology 1991;18:323-30.

9 Lautenschlager I, Höckerstedt K, Häyry P. Fine-needle aspiration biopsy in the monitoring of liver grafts. Transpl Int 1991;4:54-61.

10 Kubota K, Ericzon BG, Reinholt FP. The correlation between cytological patterns in bile and histological findings in liver transplantation. Transplantation 1992;53: ings in

11 Roberti I, Lieberman KV, Manzarbeitia C, et al. Evidence that the systematic analysis of bile cytology permits monitoring of hepatic allograft rejection. Transplantation 1992;54:471-4

12 Nakhleh RE, Schwarzenberg SJ, Bloomer J, Payne W, Snover DC. The pathology of liver allografts surviving longer than one year. Hepatology 1990;11:465-70.

13 Williams JW, Peters TG, Vera S, et al. Biopsy directed immunosuppression following hepatic transplantation. Transplantation 1985;39:589-96.

14 Wight DGD, Portmann B. Pathology of rejection. In: RY Calne ed. Liver transplantation. 2nd edn. London: Grune and Stratton, 1987:385-435.

15 Snover DC, Freese DK, Sharp HL, et al. Liver allograf rejection. An analysis of the use of biopsy in determining the outcome of rejection. Am $\mathcal{f}$ Surg Pathol 1987;11: $1-10$.

16 Riely CA, Vera SR. Liver biopsy in the long-term followup of liver transplant patients: still the gold standard. up of liver transplant patients:

17 Demetris AJ, Qian SG, Sun H, Fung JJ. Liver allograft rejection: an overview of morphologic findings. $A m \mathcal{F}$ Surg Pathol 1990;1:49-63. 
18 Kubota K, Ericzon BG, Reinholt FP. Comparison of fineneedle aspiration biopsy and histology in human liver transplants. Transplantation 1991;51:1010-3.

19 Colina F, Mollejo M, Moreno E, et al. Effectiveness of histopathological diagnoses in dysfunction of hepatic transplantation. Review of 146 histopathological studies transplantation. Review of 146 histopathological studies 998-1005.

20 Schlitt HJ, Nashan B, Ringe B, et al. Differentiation of liver graft dysfunction by transplant aspiration cytology. Transplantation 1991;51:786-93.

21 Hübscher SG. Histological findings in liver allograft rejection-new insights into the pathogenesis of hepatocellula damage in liver allografts. Histopathology 1991;18: 377-83.

22 Colina F. The role of histopathology in hepatic transplantation. Semin Diagn Pathol 1992;9:200-9.

23 Wiesner RH, Ludwig J, Krom RAF, Hay JE, van Hoek B. Hepatic allograft rejection: new developments in termiHepatic alograft rejection: new developments in terminology, diagnosis, pren

24 Wight DGD. The pathology of liver transplantation. In Wight DGD, ed. Liver, biliary tract and exocrine pancreas. 3rd edn. WStC Symmers (series ed.) Edinburgh Churchill Livingstone, 1994:543-96.

25 Snover DC, Sibley RK, Freese DK, et al. Orthotopic liver transplantation: a pathological study of 63 serial liver biopsies from 17 patients with special reference to the diagnostic features and natural history of rejection. Hepatology 1984;4:1212-22.

26 Ludwig J. Classification and terminology of hepatic allograft rejection: whither bound? Mayo Clin Proc 1989;64 $676-9$

27 Wight DGD. Cholestasis and extrahepatic bile ducts. In Wight DGD, ed. Liver, biliary tract and exocrine pancreas. 3rd edn. (WStC Symmers series ed.) Edinburgh: Churchill Livingstone, 1994:287-337.

28 Hübscher SG, Clements D, Elias E, McMaster P. Biopsy findings in cases of rejection of liver allograft. $\mathcal{f}$ Clin Pathol 1985;38:1366-73.

29 Lautenschlager I, Hockerstedt K. Induction of ICAM-1 on hepatocytes precedes the lymphoid activation of acute liver allograft rejection and cytomegalovirus infection. Transplant Proc 1993;25:1429-30.

30 Adams DH, Hübscher SG, Shaw J, Rothlein R, Neuberge $\mathrm{J}$. Intercellular adhesion molecule 1 on liver allografts during rejection. Lancet 1989;ii:1122-5.

31 Wee S-L, Cosimi AB, Preffer FI, et al. Functional consequences of anti-ICAM-1 (CD54) in Cynomolgus monkeys with renal allografts. Transplant Proc 1991;23: 279-80.

32 Wecker H, Auchinloss H. Cellular mechanisms of rejection. Curr Opin Immunol 1992;4:561-6.

33 Rosenberg AS, Munitz TI, Maniero TG, Singer A Cellular basis of skin allograft rejection across a class I major histocompatibility barrier in mice depleted of major histocompatibility barrier in mice depleted

34 Perkins JD, Wiesner RH, Banks, et al. Immunohistologic labeling as an indicator of liver allograft rejection. Transplantation 1987;43:105-8.

35 Foster PF, Sankary HN, Hart M, Ashmann M, William JW. Blood and graft eosinophilia as predictors of rejection in human liver transplantation. Transplantation 1989;47:72-4.

36 Takatsu K. Interleukin-5. Curr Opin Immunol 1992;4: 299-306

37 Yamaguchi Y, Suda T, Ohta S, et al. Analysis of the survival of mature human eosinophils: interleukin-5 previval of mature human eosinophils: interleukin-5 prevents apoptosis

38 Martinez OM, Ascher NL, Ferrell L, et al. Evidence for nonclassical pathway of graft rejection involving interleukin 5 and eosinophils. Transplantation 1993;55: 909-18.

39 Gordon RD, Iwatsuki S, Esquivel CO, Tzakis A, Starz TE. Liver transplantation across $\mathrm{ABO}$ blood groups. Surgery 1986;100:342-8.

40 Demetris AJ, Jaffe R, Tzakis A, et al. Antibody-mediated rejection of human liver allografts: transplantation acros ABO blood group barriers. Transplant Proc 1989;21: 2217-20.

41 Karuppan S, Ericzon BG, Moller E. Relevance of a posiive crossmatch in liver transplantation. Transpl Int $1991 ; 4: 18-25$.

42 Hanto DW, Snover DC, Sibley RK. Hyperacute rejection of a human liver allograft in a presensitized recipient. Clin Transpl 1987;1:304-10

43 Bird G, Friend $P$, Donaldson $P$, et al. Hyperacute rejection in liver transplantation: a case report. Transplant Proc 1989;21:3742-4

44 Gubernatis G, Kemnitz J, Bornscheuer A, Kuse ER, Pichlmayr $R$. Potential various appearances of hyperacute rejection in human liver transplantation. Langenbecks Arch Chir 1989;374:240-4.

45 Starzl TE, Demetris AJ, Todo S, et al. Evidence for hyperacute rejection of human liver grafts: the case of the canary kidneys. Clin Transplant 1989;3:37-48.
46 Hübscher SG, Adams DH, Buckels JAC, et al. Massive haemorrhagic necrosis of the liver after liver transplantation. $f$ Clin Pathol 1989;42:360-70.

47 Samuel D, Gillet D, Castaing D, Reynès MHB. Portal and arterial thrombosis in liver transplantation: a frequent event in severe rejection. Transplant Proc 1989; 21:2225-7.

48 Yanaga $\mathrm{K}$, Makowka L, Starzl TE. Is hepatic artery thrombosis after liver transplantation really a surgical complication? Transplant Proc 1989;21:3511-3.

49 Demetris AJ, Jaffe R, Tzakis A, et al. Antibody-mediated rejection of human orthotopic liver allografts. A study of liver transplantation across ABO blood group barriers. Am F Pathol 1988;132:489-502.

50 Demetris AJ, Nakamura K, Yagihashi A, et al. A clinicopathological study of human liver allograft recipients harbouring preformed IgG lymphocytotoxic antibodies. Hepatology 1992;3:671-81.

51 Davies HFS, Pollard SG, Calne RY. Soluble HLA antigens in the circulation of liver graft recipients. Transplantation 1989;47:524-7.

52 Wight DGD. Analysis of the pathological features of 40 cases of chronic liver transplant rejection. Gut 1989 30:A1500-1

53 Hübscher SG, Buckels JA, Elias E, McMaster $P$, Neuberger J. Vanishing bile-duct syndrome followin liver transplantation-is it reversible? Transplantation 1991;51:1004-10.

54 O'Grady J, Williams R. Long-term management, complications, and disease recurrence. In: Maddrey WC, ed. Transplantation of the liver. Current topics in gastroenterology. New York: Elsevier, 1988:143-65.

55 Billingham ME. Cardiac transplant atherosclerosis. Transplant Proc 1987;19:19-25.

56 Oguma S, Belle S, Starzl TE, Demetris AJ. A histometric analysis of chronically rejected human liver allografts. Insight into the mechanisms of bile duct loss: direct immunologic and ischaemic factors. Hepatology 1989;9: 204-9.

57 Gravanis MB. Allograft heart accelerated atherosclerosis: evidence for cell-mediated immunity in pathogenesis. Mod Pathol 1989;2:495-505.

58 Tanaka $M$, Umihara J, Shimmoto $K$, et al. The pathogenesis of graft-versus-host reaction in the intrahepatic bile duct An immunohistochemical study. Acta Pathol fpn 1989;39:648-55.

59 Chao NJ. Graft versus host disease following allogeneic bone marrow transplantation. Curr Opin Immunol 1992;4:571-6.

60 Nonomura A, Kono N, Mizukami Y, Nakanuma Y. Histological changes of the liver in experimental graftversus-host disease across minor histocompatibility barriers. VII. A light and electron microscope study of the large bile duct. Liver 1993;13:163-71.

61 Donaldson P, Underhill J, Doherty D, et al. Influence of HLA matching on liver allograft survival and rejection: the dualistic effect. Hepatology 1993;17:1008-15.

62 O'Grady J, Alexander GJM, Sutherland S, et al. Cytomegalovirus infection and donor/recipient HLA antigens: interdependent co-factors in pathogenesis of vanishing bile-duct syndrome after liver transplantation. Lancet 1988;ii:302-5.

63 Arnold JC, Portmann BC, O'Grady JG, et al. Cytomegalovirus infection persists in the liver graft in the vanishing bile duct syndrome. Hepatology 1992;16: 285-92.

64 Beck S, Barrell BG. Human cytomegalovirus encodes a glycoprotein homologous to MHC class I antigens. Nature 1988;331:269-72.

65 Wright TL. Cytomegalovirus infection and vanishing bile duct syndrome: culprit or innocent bystander [editorial] Hepatology 1992;16:494-6.

61 Paya CV, Wiesner RH, Hermans PE, et al. Lack of association between cytomegalovirus infection, HLA matching and the vanishing bile duct syndrome after liver transplantation. Heptology 1992;16:66-70.

67 Starzl TE, Demetris AJ, Murase N, et al. Cell migration, chimerism and graft acceptance. Lancet 1992;339: 1579-82.

68 Starzl TE, Demetris AJ, Trucco $M$, et al. Systemic chimerism in human female recipients of male livers. chimerism in human fet

69 Starzl TE, Demetris AJ, Trucco M, et al. Cell migration and chimerism after whole-organ transplantation: the

70 Porter KA. Pathology of the orthotopic homograft and heterograft. In: Starzl TE, ed. Experience in hepatic transplantation. Philadelphia: WB Saunders, 1969:422-71.

71 Selby R, Starzl TE, Yunis E, et al. Liver transplantation for type IV glycogen storage disease. N Engl $\mathcal{F}$ Med 1991; 324:39-42.

72 Steinman RM, Inaba K, Austyn JM. Donor-derived chimerism in recipients of organ transplants [editorial]. Hepatology 1993;17:1153-6.

73 Judge T. Mixed chimerism after transplantation: mechanism or marker of specific tolerance? Hepatology 1993; 17:943-5. 